\title{
Developing Microbial Inocula to Support Biofuel Crop Cultivation on Tributyltin Contaminated Marine Sediments
}

\author{
Christopher Finnegan*, David Ryan, Anne-Marie Enright, Guiomar Garcia-Cabellos \\ Enviro CORE, Institute of Technology Carlow, Kilkenny Road, Carlow, Ireland \\ *Corresponding author: Christopher.finnegan@itcarlow.ie
}

\begin{abstract}
Tributyltin (TBT) is a synthetic organotin compound and is recognised as the most toxic chemical ever knowingly introduced into the marine environment. Organotins have a wide range of application with an estimated global production of 50,000 tons per year therefore impacts from TBT can be seen or anticipated in many environments including protected areas like aqua farms and world heritage sites effecting aquaculture and undisturbed ecosystems. Due to the impact of TBT a necessity exists for the treatment of contaminated sediment and soil using nature-based solutions as it is both non-invasive and sustainable. However these remediation techniques must also be economically interesting to increase its acceptance. Thus using the biomass from plant species with the ability to cultivate in dredged sediment for biofuel and biomaterials production should be considered to ensure that renewable energy consumption of $10 \%$ is meet by 2020 . The objectives of this study is to investigate the potential of Hordeum vulgare and Brassica napus to cultivate in marine sediments despite the salinity and TBT pollution for a 30 day pot trial. Further to inoculate seedling roots with known TBT degrading bacteria to enhance the phytoremediation capacity. Also to establish if bacterial isolates C7 and C22 are plant growth promoting bacteria. Statistical analysis on seedlings biomass was carried out followed by analytical analyses by atomic absorption spectroscopy (AAS) and sediment analysis by gas chromatography mass spectrometry (GC-MS). Results showed a maximum decrease of $\geq 82 \%$ and $\geq 80 \%$ of TBT in sediment samples respectively with bacteria inoculum C7 (KX881905) and C22 (KX881904), further Hordeum vulgare seedlings were the ideal candidate plant species with a significant production of biomass.
\end{abstract}

Keywords: bioremediation, crop cultivation, gas chromatography, phytoremediation, microbial interactions, marine sediments

Cite This Article: Christopher Finnegan, David Ryan, Anne-Marie Enright, and Guiomar Garcia-Cabellos, "Developing Microbial Inocula to Support Biofuel Crop Cultivation on Tributyltin Contaminated Marine Sediments." Journal of Applied \& Environmental Microbiology, vol. 5, no. 2 (2017): 47-56. doi: 10.12691/jaem-5-2-1.

\section{Introduction}

Tributyltin (TBT, $\mathrm{C}_{12} \mathrm{H}_{27} \mathrm{Sn}^{+}$), is one of the most toxic xenobiotics ever produced and deliberately introduced into the environment, TBT is an organic derivative of tin, characterised by the presence of covalent bonds between three carbon (C) atoms and a single tin atom $\left(\mathrm{Sn}^{4+}\right)[1,2,3]$. TBT and other organotins have been used in industrial applications for PVC production, marine antifouling paints, agricultural pesticides and fungicides, and numerous consumer products and household items [1,3-8]. Consequently, this widespread use has led to an environmental presence in soil, sediment, water and biota where it has been detected in coastal waters at concentrations of $\geq 500 \mathrm{ng} \mathrm{Sn} / \mathrm{l}$ and in harbours and shipping lane sediments up to $16,800 \mathrm{ng} \mathrm{Sn/g} \mathrm{[1].} \mathrm{The}$ presence of TBT in aquatic environment has had unfortunate consequences for non-target organisms, for example the near collapse of the pacific oyster fishery
(Arcachon Bay, France). TBT is a known endocrine disruptor and is most notably associated with imposex in the periwinkle (Littorina littorea) and dog-whelk (Nucella lapillus) populations. This phenomenon is considered the best example of endocrine disruption in wildlife to date with TBT concentrations as low as $1 \mathrm{ng} / \mathrm{l}$ of TBT resulting in observable effects $[2,7,8,9]$. TBT has also been implicated in causing damage to the aquatic food web by preventing the growth of phytoplankton, vital primary producers, and by bioaccumulation and biomagnification in other marine species $[1,6,8,10]$. Furthermore, TBT is lipophilic and has been detected in the liver and fat cells of animals of higher tropic levels such as: fish, birds, seals, sharks, porpoises and whales at levels up to $790 \mathrm{ng} \mathrm{Sn/g}$ causing lethal mutagenic effects and damage to the central nervous systems [1].

Despite the global treaty called in January 2001 by the International Maritime Organization (IMO), which prohibits the use of TBT based paints, impacted aquatic organisms have not yet recovered. This is unsurprising as TBT levels in these environments still surpasses the 
maximum allowable environmental quality standard of 1.5 ng $\mathrm{Sn} / 1$ [11]. This is mainly due to failure of legal restrictions in various countries and also the high specific gravity of TBT $\left(1.2 \mathrm{~kg} / \mathrm{l}\right.$ at $\left.20^{\circ} \mathrm{C}\right)$. This is further compounded by the fact that in these environments TBT bonds to suspended material, such as sediment, where it can persist unaltered for decades under anaerobic conditions [2]. Marine pollution does not distinguish national, regional or conservation boundaries, therefore impacts from TBT can be seen or anticipated even in protected areas like aqua farms and world heritage sites effecting aquaculture and undisturbed ecosystems such as the Antarctica and the Great Barrier Reef [12,13,14].

Recent studies have also demonstrated that TBT pollution is not restricted to harbour or open ocean areas as concentrations of TBT in freshwaters and freshwater sediments have been estimated to reach $7.1 \mu \mathrm{g} / \mathrm{l}$ and 3700 $\mu \mathrm{g} / \mathrm{kg}$, respectively indicating its potential impact on freshwater biota [15]. As a result of additional pathways, such as the disposal of organotin containing products and the dumping of dredged marine and freshwater sediment in landfill, the contamination of soil and ground waters is also of concern $[2,3,6]$.

Therefore, environmental concentrations of TBT remain high enough to motivate action. Restoring TBT contaminated ecosystems using nature-based solutions, such as bioremediation, is both non-invasive and sustainable. Several studies have suggested marine and estuarine bacterial are the primary pathway for TBT removal via biological degradation, in particular the genera, Alcaligenes, Aeromonas, Enterobacter, Bacillus and Pseudomonas [5,8,16-21].

In addition, phytoremediation is a proven method employed for the clean-up of sites contaminated with various pollutants including; heavy metals, pesticides and volatile and nonvolatile organic compounds [22]. Nevertheless, it should be noted that plant based technologies have certain limitations and not ideally suited for the break down and metabolism of organic compounds. Therefore the combination of bacterial TBT degraders and salt tolerant plants, which will dewater the sediment and allow for aeration, could increase the process time and remediation ability [2].

Combining these methods could represent an environmentally friendly, cost-effective and carbon neutral way to clean up pollutants specifically when compared to physicochemical methods such as thermal treatment, steam striping and chemical oxidation or direct disposal via landfilling [2,5,8,23]. Moreover, nature-based solutions can improve resource efficiency by providing a range of alternative sources of energy from resulting by-product such as biofuels and biomaterials (Figure 1). For example, barley grain can be used to produce ethanol [24] and recent advancements have made it possible to produce cellulosic biofuels from inedible biomass, such as stems, leaves and stalks [24,25]. Furthermore, waste dried distillers grains can be used to produce an energy-rich oil called bio-oil. Importantly, biofuels produced from energy crops have emerged as one of the most significant sustainable energy sources which have the potential to meet $\geq 75 \%$ of current petrol demands [26,27]. Thus generate new economic opportunities for agriculturalists on non-agricultural lands [28].

The overall aim of this study is to develop a naturebased solution, combining both phytoremediation and bioremediation elements, to clean up contaminated TBT sediment. In a previous study by the authors [29], TBT resistant bacteria from both soil and sediment samples were isolated and characterised via biochemical and $16 \mathrm{~S}$ rRNA gene sequence analysis (Figure 2). In particular, two bacterial isolates C7 (KX881905) and C22 (KX881904) recorded high TBT removal rates, $\geq 69 \%$ over 21 days, [29], exhibiting a breakdown of TBT through sequential dealkylation (Figure 3). To this end isolates C7 and C22 were selected for the development of the bacterial inoculum used in the current study, as they represent two new unstudied high resistance TBT degraders.

The objectives of this study may be summarised as follows: (1) determine the phytotoxic effect of various TBT concentrations on seed germination; (2) to investigate the potential of Hordeum vulgare and Brassica napus to degrade/bio-accumulate TBT in sediment and soil; (3) to inoculate seedling roots with known TBT degrading bacteria to enhance the phytoremediation capacity of Hordeum vulgare and Brassica napus seedlings; and (4) to establish if bacterial isolates C7 and C22 are plant growth promoting bacteria, with the aim of employing the contaminated sediment to cultivate plants for biofuels and biomaterial.

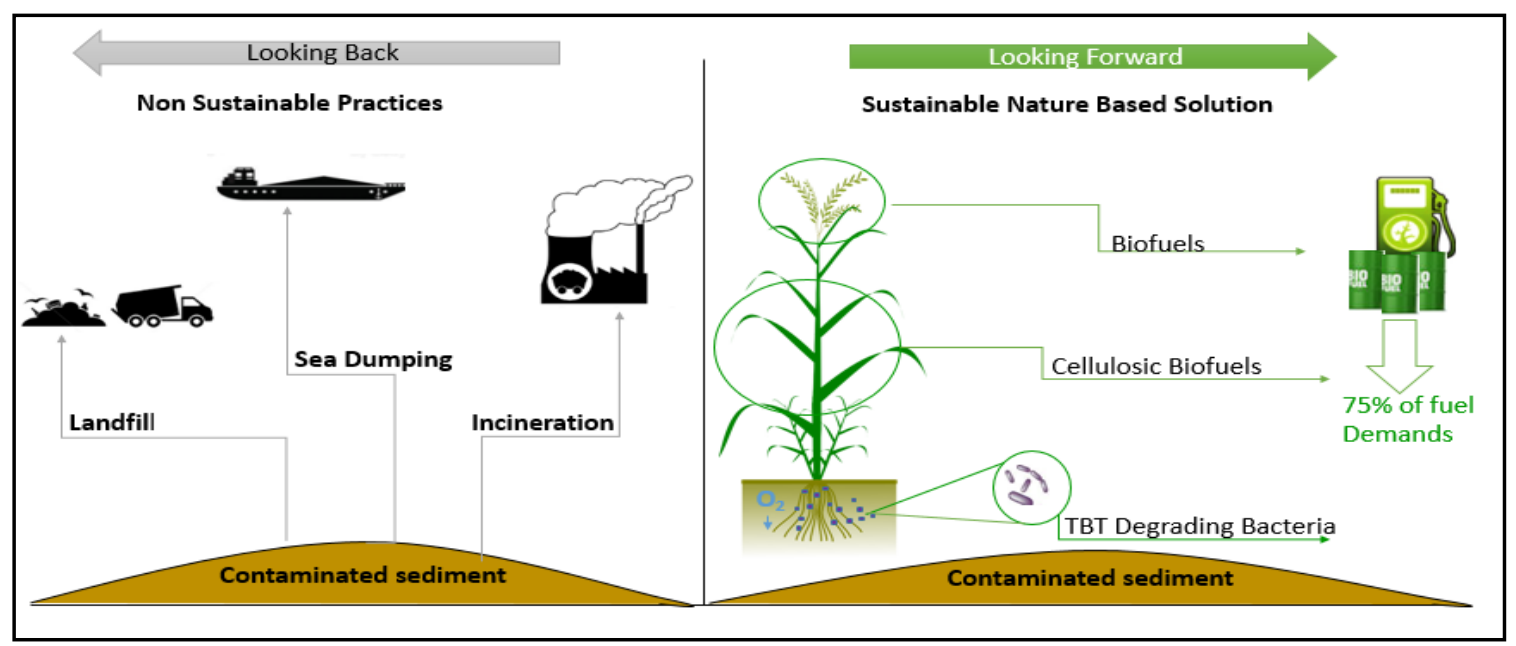

Figure 1. Looking forward nature-based solutions can improve resource efficiency, providing a range of alternative sources of energy from the byproduct of treated contaminated sediment or soil 




Figure 2. Phylogeny of bacterial sequences based on the Kimura-2 model and the neighbour-joining method of Saito and Nei (1987). Bootstrap replicates (out of a total of 100 replicate samplings) that supported the branching order are shown at relevant nodes. The scale bar represents 1 nucleotide substitution per 100 sequence position

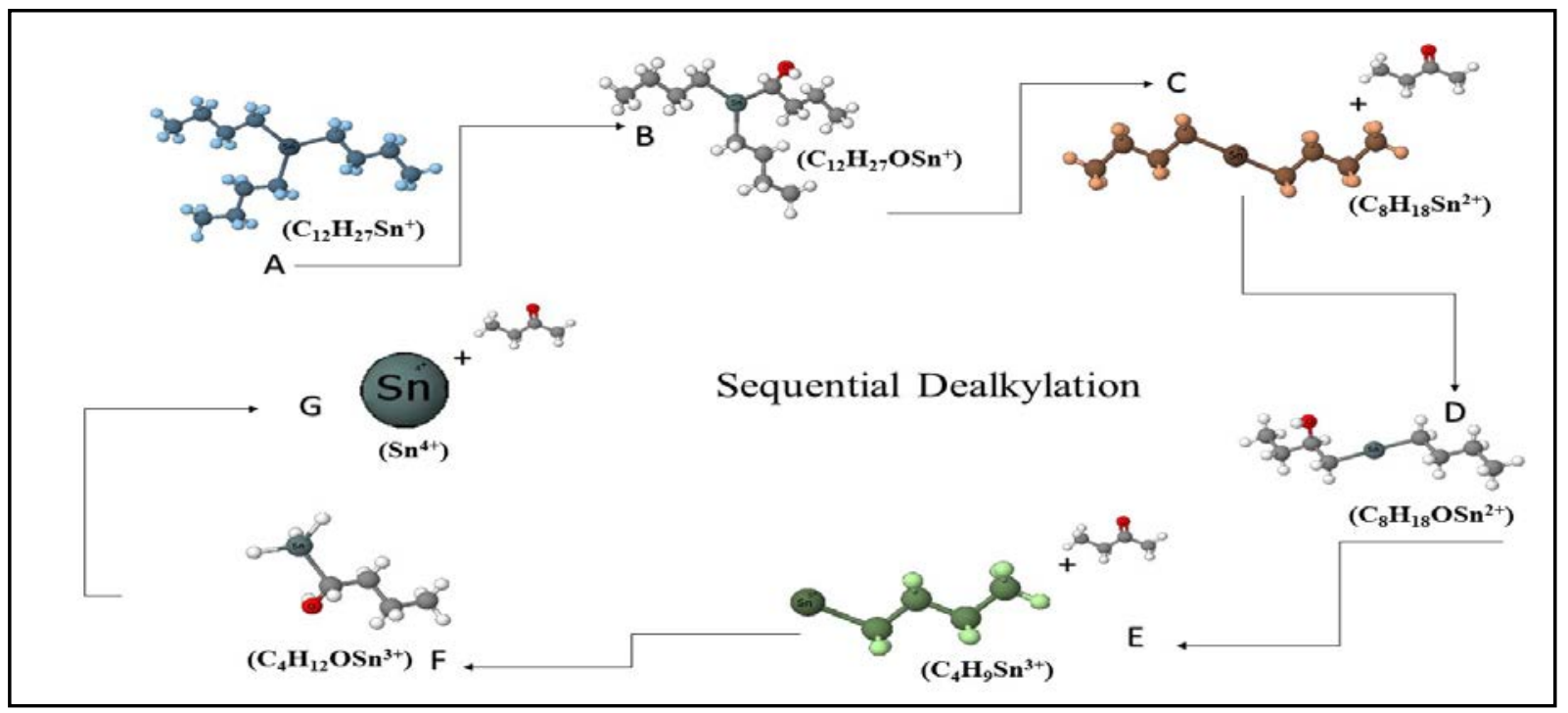

Figure 3. Degradation of TBT by sequential dealkylation. (A) TBT $\left(\mathrm{C}_{12} \mathrm{H}_{27} \mathrm{Sn}^{+}\right)$forms (B) $\beta$-hydroxybutyl-dibutyltin $\left(\mathrm{C}_{12} \mathrm{H}_{27} \mathrm{OSn}^{+}\right)$through Dioxygenases (incorporating an oxygen atom into the substrate through enzyme activity), to (C) DBT $\left(\mathrm{C}_{8} \mathrm{H}_{18} \mathrm{Sn}^{2+}\right)$ and methyl ethyl ketone. (D) $\beta$ hydroxybutyl-butyltin $\left(\mathrm{C}_{8} \mathrm{H}_{18} \mathrm{OSn}^{2+}\right)$ degrades to (E) MBT $\left(\mathrm{C}_{4} \mathrm{H}_{9} \mathrm{Sn}^{3+}\right)$ and methyl ethyl ketone. (F), $\beta$-hydroxybutyl $\left(\mathrm{C}_{4} \mathrm{H}_{12} \mathrm{OSn}^{3+}\right)$ to $(\mathrm{G})$ tin $\left(\mathrm{Sn}^{4+}\right)$ and methyl ethyl ketone [1]

\section{Materials and Methods}

\subsection{Chemicals and Reagents}

All chemicals and reagents were purchased from Sigma-Aldrich Ireland unless otherwise stated. Tributyltin chloride (TBT 95\%) dibutyltin dichloride (DBT 97\%) and butyltin trichloride (MBT, 95\%). Individual stock solutions of MBT, DBT, and TBT were prepared in methanol (99.7\%, GC grade) and were kept in the dark at $-4^{\circ} \mathrm{C}$. Sodium tetraethylborate NaBEt4 (97\%, Fisher Scientific Ireland) was used as the derivatisation agent. $1 \mathrm{~g}$ of NaBEt4 dissolved in $20 \mathrm{ml}$ of tetrahydrofuran (HPLC Grade, Sci-Chem Ireland). Sodium acetate (82 g/l sodium acetate in deionised $\mathrm{H}_{2} \mathrm{O}, \mathrm{pH}$ 4.7), acetic acid and sodium hydroxide was used to adjust the $\mathrm{pH}$. 2, 2, 4-trimetylpentane (99\% Fisher Scientific Ireland) was used for extraction. Tin stock solutions and working standards were prepared in HNO3 acidified double deionised water from Sn $1.000 \mathrm{~g} / \mathrm{l}$ for AAS (LENNOX laboratory supplies limited).

\subsection{Seed Material}

Seeds of spring barley Hordeum vulgare $L$ var. KWS IRINA and spring oilseed rape Brassica napus var. Tamarin of uniform size, colour and weight were selected for all experimental work. All seeds, for each repetition of each treatment were from the same batch and year.

\subsection{Germination Trial}

Seed germination was conducted to establish the phytotoxic effect of TBTCl methanol solution using various concentration $(0,1,5,10,50,100,500$ and $1000 \mathrm{mg} \mathrm{l}^{-1}$ ). Seeds were geminated in $9 \mathrm{~cm}$ petri dishes (5 seeds evenly spaced per dish) on 2 sheets of Whatman No. 1 filter paper moistened with distilled water. Two 
seed treatment methods were employed. Method 1 involved pipetting $500 \mu \mathrm{l}$ of the different concentrations of TBTCl onto each individual seed. Petri dishes were then covered with parafilm and incubated for $120 \mathrm{hrs}$ at $20^{\circ} \mathrm{C}$. In Method 2 the filter papers were pre-soaked in TBTCl solutions $(5 \mathrm{ml})$ at various concentrations before seeds were placed on top. Both methods were carried out in triplicate with untreated seeds employed as controls. After incubation, germinated seedlings of Hordeum vulgare and Brassica napus with $5 \mathrm{~mm}$ radical length [30], [31] were separated and counted to calculate percent germination by the following formula: \% $\mathrm{G}=$ (Number of germinated seeds/Total number of seeds) $\mathrm{x} 100$. The germination trials were carried in quadruplicate.

\subsection{Source of TBT Degrading Isolates and TBT free Sediment}

Two TBT degrading bacterial isolates, C7 (KX881905) and C22 (KX881904), previously characterised and identified by the authors were utilised in this study [29]. C7 was isolated from soil samples from a traverser pit located on Dinish Island in Bear Heaven, approximately $2 \mathrm{~km}$ from Castletownbere, Co Cork. Isolate C22 was isolated from sediment samples obtained from Haulbowline, a $0.339 \mathrm{~km} 2$ island in Cork harbour (latitude 51 ${ }^{\circ} 50$ '43.8', north and longitude $8^{\circ} 16^{\prime} 35.8^{\prime \prime}$ west). Sediment samples were collected from Courtown beach latitude 52 ${ }^{\circ} 38^{\prime} 53.4^{\prime \prime}$ north and longitude $6^{\circ} 13 ' 33.5^{\prime \prime}$ west Co. Wexford Ireland were no known pollution of TBT has taken place.

\subsection{Generation of Microbial Inoculum}

C7 and C22 isolates were aseptically inoculated into a nutrient broth $(10 \mathrm{ml})$ and incubated at $37^{\circ} \mathrm{C}$ at $100 \mathrm{rpm}$ for 24 hrs. Bacterial cells with a typical cell count of 108 to 109 cells $/ \mathrm{ml}^{-1}$ were centrifuged in $50 \mathrm{ml}$ falcon tubes at $3000 \mathrm{rpm}$ for 15 mins, using a Hettich Rotanta 460 centrifuge. The resulting pellet was recovered and resuspended in $10 \mathrm{ml}$ of $1 / 4$ strength sterile ringer's solution. Individual seedlings of Hordeum vulgare and Brassica napus were placed in petri dishes and $500 \mu \mathrm{l}$ of the inoculum was pipetted onto the root of each seedling under sterile conditions and allowed to absorb for 3 hrs before transplanting to pots.

\subsection{Sediment and Soil Preparation}

The sediment samples were air dried for 72 hours prior to supplementation with 1,10 and $50 \mathrm{mg} / \mathrm{kg}$ of tributyltin chloride in a $99.7 \%$ methanol solution. Air dried sediment without TBT supplementation was retained for use as a control. The contaminated sediment was then air dried for 1 week and homogenised by mixing twice daily before potting.

\subsection{Plant Trial Design}

Pre-germinated seedlings of Hordeum vulgare and Brassica napus, as described above, were planted into artificially polluted sediment in pots. The experimental controls were as follows; untreated seedlings in TBT-free soil and untreated seedling in TBT-free sediment, all controls and experimental pots were carried out in triplicate. The plant trial was conducted in a plant growth room with a photoperiod of $12 \mathrm{hrs}$ at $20^{\circ} \mathrm{C}$. Each pot was watered with $20 \mathrm{ml}$ of deionised water three times per week. The salinity of sediment ranged between 8-16 decisiemens per metre $(\mathrm{dS} / \mathrm{m})$. The plant trial was arranged in a complete randomised block design with 3 replicates for each treatment with 5 seeds sown at uniform distance in each pot (Figure 4). Seedlings were harvested after 30 days to analytically establish the removal of TBTCl from contaminated sediment. The biomass (dry weight; g) of inoculated plants was compared against noninoculated plants grown in soil and contaminated sediment samples to establish if bacteria strains promoted plant growth under adverse conditions.

\subsection{Total Sn Analysis}

Harvested seedling samples were cleaned by sequentially rinsing, once with tap water and twice with deionised water to remove adhering materials before being oven dried at $60^{\circ} \mathrm{C}$ for $48 \mathrm{hrs}$. Seedling samples $(1 \mathrm{~g})$ were digested in an open-vessel acid digestion using nitric acid $\left(\mathrm{HNO}_{3}\right)$ and hydrogen peroxide $\left(\mathrm{H}_{2} \mathrm{O}_{2}\right)$ at a ratio of 3:1 which was gently heated to $90^{\circ} \mathrm{C}$ for $20-30$ mins. After digestion, the suspension was filtered (quantitative filter paper particle retention: 2-3 $\mu \mathrm{m}$, Cell acetate syringe filter, $0.45 \mu \mathrm{m})$ and diluted using $\mathrm{ddH}_{2} \mathrm{O}$ to a final volume of 25 $\mathrm{ml}$ (1/25 dilution factor). The resulting samples were analysed for total tin (Sn) uptake via flame atomic absorption spectroscopy, Agilent (Tec 200 AA series). The instrumental conditions were as follows; a single beam instrument incorporating a tin hollow-cathode lamp (Agilent) with air-acetylene flame with an adjustable nebuliser and a wavelength of $235.5 \mathrm{~nm}$ for an optimum working range of $1-200 \mu \mathrm{g} \mathrm{ml}$.

\subsection{Sediment Sample Derivatisation}

Sediment samples were collected in sterile glass sample bottles from the roots of harvested seedling via shaking vigorously for 2 mins followed root rinsing with deionised water to remove adhering material. The collected sediment samples $(0.5 \mathrm{~g})$ were dissolved in $1 \mathrm{ml}$ of acetate buffer (82 g l/l sodium acetate in deionised $\mathrm{H}_{2} \mathrm{O}, \mathrm{pH}$ 4.7). A 5\% NaBEt4 solution was then added dropwise, total addition of $4 \mathrm{ml}$, under continuous sonication for ethylation. After sample derivatisation the $\mathrm{pH}$ was adjusted to 12.5 dropwise with $1 \mathrm{M}$ sodium hydroxide solution to decompose boroxin side reactions, ethylated butyltin compounds were not affected [3]. Samples were then extracted with $5 \mathrm{ml}$ of $99.7 \%$ methanol. This step was repeated 4 times to ensure organotins were removed, followed by the addition of $1 \mathrm{ml}$ of 2, 2, 4-trimetylpentane. Suspensions were centrifuged at $4000 \mathrm{rpm}$ for $15 \mathrm{~min}$ resulting in the separation of sample into two phases. The organic layer was then concentrated by rotary evaporation to $3 \mathrm{ml}$ and further evaporated down to $1 \mathrm{ml}$ by a gentle stream of nitrogen.

\subsection{GC-MS Operating Conditions.}

The separation and detection of organotin species TBT, DBT and MBT was performed by a Varian 450-GC, 
220-MS system, with CombiPAL auto sampler (Varian Inc., Walnut Creek, CA). Separation was carried out on a capillary column coated with 5\% biphenyl and 95\% dimethylpolysiloxane (30 m length $\mathrm{x} 0.25 \mathrm{~mm}$ internal diameter $\mathrm{x} .25 \mu \mathrm{m}$ film thickness). The injector volume was $1 \mu \mathrm{l}$ in a splitless injection mode and injector temperature was maintained at $280^{\circ} \mathrm{C}$. Helium was employed as the carrier gas, at a flow rate of $1 \mathrm{ml} \mathrm{min}^{-1}$. The temperature program was as follows: $50^{\circ} \mathrm{C}(1 \mathrm{~min})$ to $300^{\circ} \mathrm{C}(4 \mathrm{~min})$ at a rate of $10^{\circ} \mathrm{C} \mathrm{min}^{-1}$ [29]. The MSdetector was operated in full scan mode in the range of 40$650 \mathrm{~m} / \mathrm{z}$ and selective ion monitoring mode (SIM) at a temperature of $280^{\circ} \mathrm{C}$. Peak area integration was used for quantitative calculation using the external standard method, peaks in the chromatograms were assigned to individual ethyl -derivatives of organotin compounds on the basis of retention time and identified using the comparison of their ion trap mass spectra with the standard MS spectra from the Standards and Technology (NIST) Mass Spectrometry Library, (Edition 2008).

\subsection{Data Analysis}

Two way analysis of variance (ANOVA, Two-Factor with Replication) was used to analyse the data among treatments for germination trial and pot trial. The data was expressed as mean standard deviation with each assay conducted in triplicate $(n=3)$. The significance level was set at $\mathrm{p} \leq 0.05$ for all statistical test.

\section{Results and Discussion}

\subsection{Phytotoxic Effect of TBT on Seed Germination}

A two way analysis of variance was used to determine the phytotoxic effect of various TBT concentrations 1,5 , $10,50,100,500$ and $1000 \mathrm{mg} \mathrm{l}^{-1}$ on seed germination of Hordeum vulgare and Brassica napus to test the following hypothesis: A null hypothesis, ( no difference will be observed between plant species Hordeum vulgare and Brassica napus on seed germination percentage) and B null hypothesis, (no difference will be observed between the various TBT concentrations on seed germination percentage). The results show a p-value (plant species) $=$ $0.541903 \geq .05=\alpha$, therefore we fail to reject the A null hypothesis, and conclude that there is no significant effect of the plant species on the seed germination. Further the p-value $($ TBT concentration $)=6.5697 * 10-09 \leq .05=\alpha$, we reject the null hypothesis $\mathrm{B}$, thus TBT concentration had a highly statistically significant impact on the seed germination.

\subsubsection{Pot Trial}

Pot studies are beneficial compared to field studies as they provide independence from seasonal limitations and afford the opportunity to minimise heterogeneity of TBT contaminated sediment samples. When designing pot studies careful and statistically sensible design is critical to ensure conclusive results thus the plant trial was arranged in a complete randomised block design with three replicates for each treatment with five seeds $(n=15)$, making the trial achievable without compromising the quality of data (Figure 4).

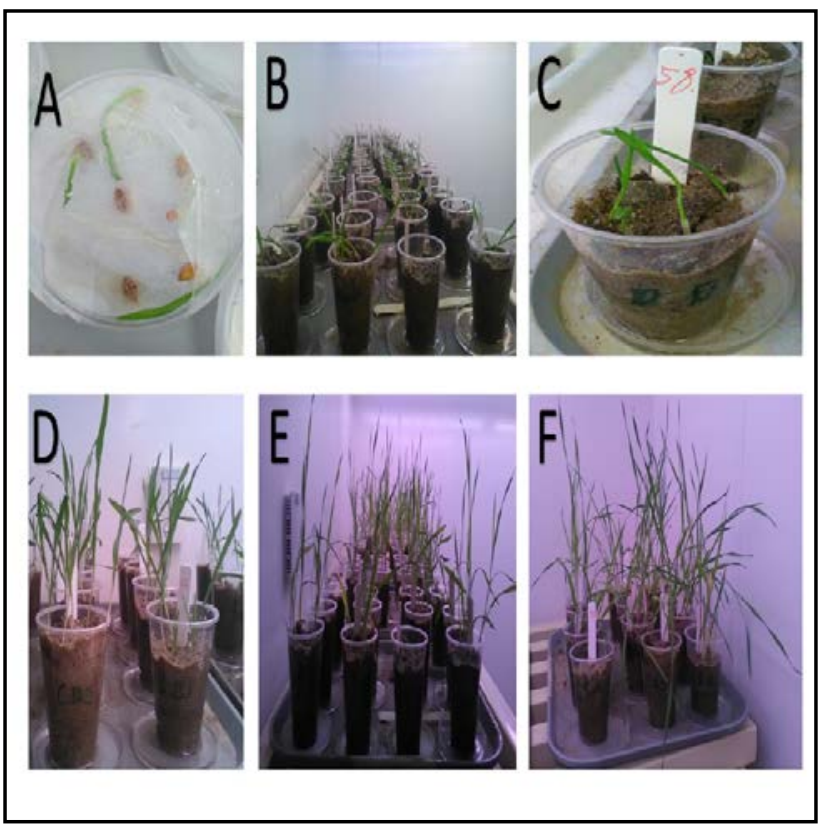

Figure 4. Pre-germinated seedlings of Hordeum vulgare (A), Pot trial day $0,(\mathrm{~B}, \mathrm{C})$, day 10, (D), day 20, (E), day 30 (F)

Throughout the plant trial $\mathrm{pH}$ was constantly monitored and pots remained at $\mathrm{pH} 6.5 \pm 0.2$ on the grounds that TBT will remain adsorbed to sediment organic matter and clay particles in between acidic $\mathrm{pH} \leq 5$ and alkaline $\mathrm{pH} \geq$ 8.1. In addition care was taken to avoid excessive watering and leachates were collected for analysis. Results showed as expected TBT did not leach from pots as correct $\mathrm{pH}$ was maintained and due to the fact that TBT is only slightly water soluble.

Unexpectedly results disclosed Brassica napus although a known salt tolerant plant showed no growth to little growth with a high percentage death rate of $74 \%$ after 13 days and $90 \%$ after 30 days of the plant trial in non-contaminated and TBT contaminated sediment. However Brassica napus did cultivate in control soil pots and also pots with and without bacteria inoculum (data not shown). To this end, Brassica napus seedlings were not analysed further.

\subsubsection{Data analysis of Biomass In Non-contaminated Pots}

Statistical data from the 30 day pot trial was used to investigate the total dry biomass of Hordeum vulgare and to test the following hypothesis and interactions: A null hypothesis, (there is no difference between seedlings of Hordeum vulgare inoculated or not inoculated with bacteria for total dry biomass) and B null hypothesis, (there is no difference between soil or sediment pots for total biomass of Hordeum vulgare). In addition the null hypothesis $\mathrm{C}$ states (there is not a significant interaction between the bacteria inoculums and the type of environment). The following was observed, the p-value (bacteria inoculums) $=0.9502 \geq .05=\alpha$, thus we fail to reject the factor A null hypothesis, and conclude (with 95\% confidence) that there are no significant differences 
between bacterial inoculums C7, C22 and non-inoculated seedlings on the total biomass of Hordeum vulgare in non-contaminated sediment and soil. Further the p-value (sediment or soil pots) $=.00025 \leq .05=\alpha$, thus we reject the factor $\mathrm{B}$ null hypothesis, and conclude that the environment for cultivating Hordeum vulgare is statistically different.

The observed p-value for the interaction between bacteria inoculums and type of environment $=0.0067$ $\leq .05=\alpha$, we reject the null hypothesis. Arising from this, the effect of different bacterial strains of total dry biomass depends on the type of environment as shown in Figure 5.

\subsubsection{Data Analysis of Biomass In Contaminated Pots}

In addition a two way analysis of variance was also used to analyse the data from the total dry biomass of Hordeum vulgare in contaminated sediment 1, 10 and 50 $\mathrm{mg} \mathrm{kg}^{-1}$ respectively to test the following hypothesis: A null hypothesis, (TBT polluted sediment 1, 10 and $50 \mathrm{mg}$ $\mathrm{kg}-1$ will have no effect on the biomass of Hordeum vulgare) and B null hypothesis, (bacteria inoculum will have no effect on the biomass of Hordeum vulgare in TBT polluted sediment). The observed p-value (TBT concentration) $=0.002127 \leq .05=\alpha$, as such we reject the A null hypothesis, and determine that there is a significant effect of TBT concentration on the biomass of Hordeum vulgare. Furthermore, the p-value (Hordeum vulgare with bacteria inoculum/without) $=0.001486 \leq .05=\alpha$, thus we reject the $\mathrm{B}$ null hypothesis also and conclude that there is a significant effect of bacteria inoculum C7 and C22 on the biomass in sediment. To conclude the bacteria inoculant C22 will not hinder the growth of Hordeum vulgare seedlings unlike bacteria inoculum C7 which effects the growth of Hordeum vulgare seedlings negatively as seen in Figure 6.

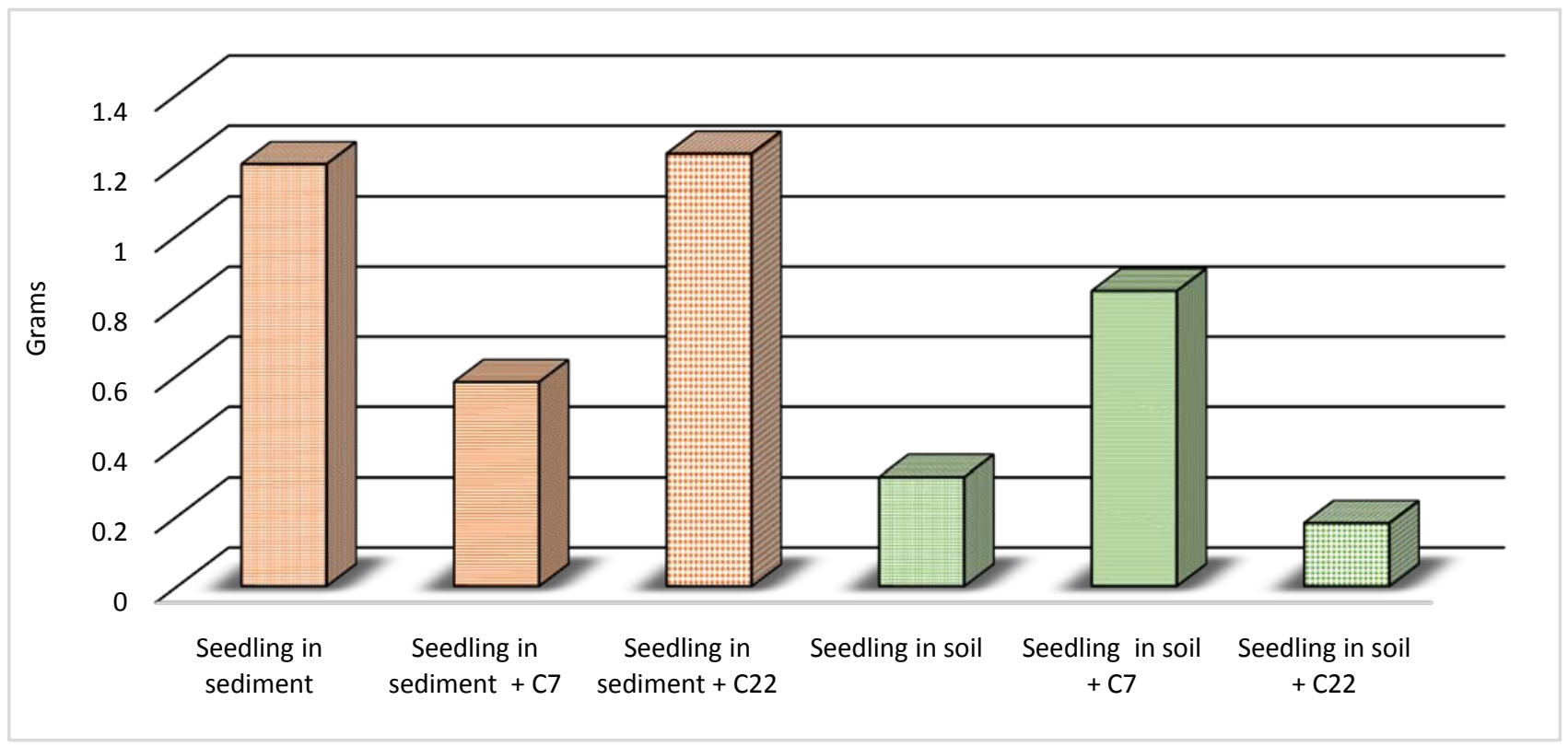

Figure 5. Total dry biomass grams, of Hordeum vulgare after 30 days (pot trial) in non-contaminated sediment and soil. Data presented as mean \pm standard deviation $(\sigma) . \mathrm{n}=15$

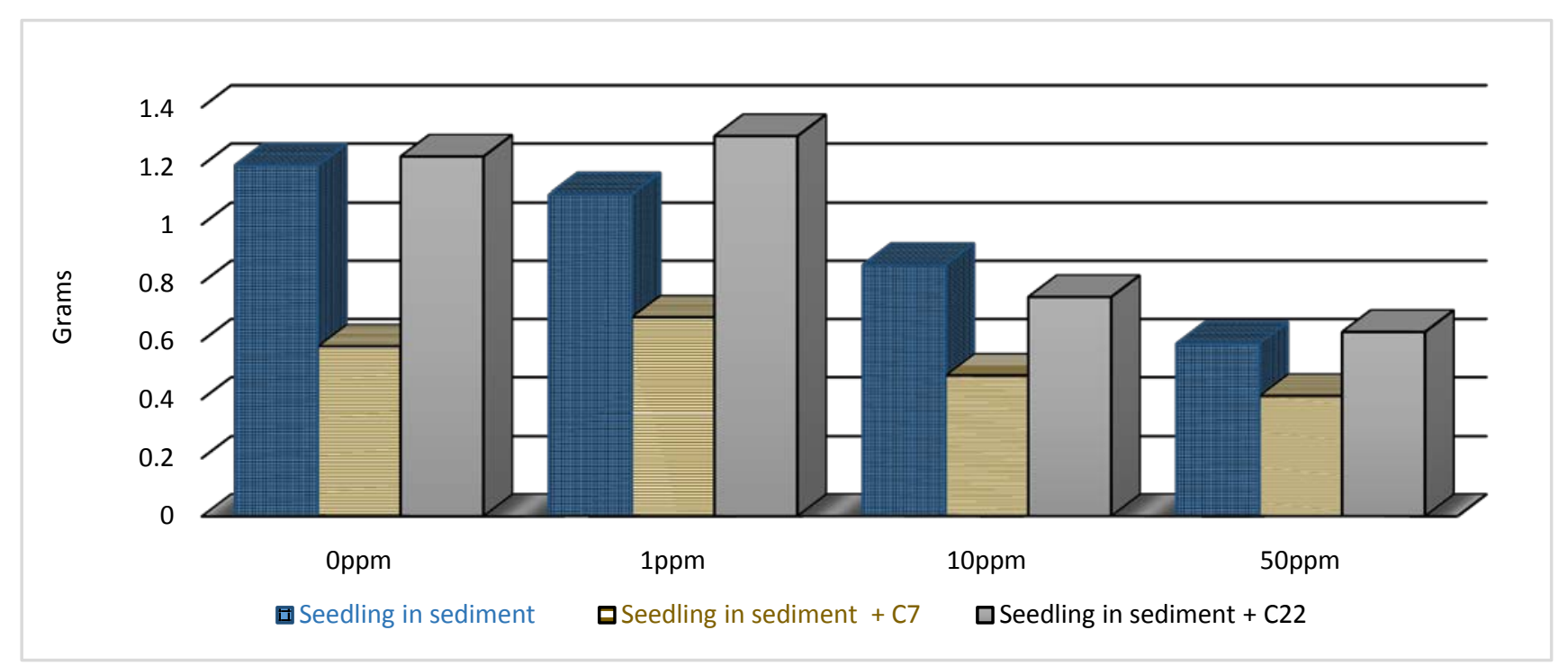

Figure 6. Effect of TBT concentrations $\mathrm{mg} \mathrm{kg}^{-1}$ (x- axis) on total dry biomass grams (y-axis) of Hordeum vulgare with bacteria inoculum/without after 30 days. Data presented as mean \pm standard deviation $(\sigma) \mathrm{n}=15$ 


\subsection{Total Sn Uptake Hordeum vulgare}

Several analytical techniques and methods have been used to determine inorganic and organotin compounds in the environment including atomic absorption spectroscopy which follows Beer-Lambert law (Absorbance $=$ e L c) [32]. In this method a total of 12 samples containing seedlings of Hordeum vulgare $\mathrm{n}=15$ per sample was analysed for total $\mathrm{Sn}$ also four composite pot samples $n=9$ containing $1 \mathrm{~g}$ of sediment of $0,1,10$ and $50 \mathrm{mg} \mathrm{kg}^{-1}$ of TBT. A calibration curve was generated from Sn standard solutions at variable concentrations $(0,1,1.5,2.5,3.5,4.5$ and $5.5 \mathrm{mg} \mathrm{l}^{-1}$ ) to identify a linear range. Unfortunately it was discovered that the limit of detection of the instrument was $3 \mathrm{mgl}^{-1}$ of $\mathrm{Sn}$, to overcome this a novel approach was taken to spike each sample with $20 \mathrm{mgl}^{-1}$ of a Sn standard solution. A calibration cure was established for quantitative analysis measuring concentration vs absorbance with a working range of $10-50 \mathrm{mgl}^{-1}$ of Sn with a correlation coefficient $\mathrm{R}^{2}$ of 0.9999 . Concentration of the added Sn solution was established from the mean, value of 10 replicate sample \pm the standard deviation $(\sigma)$ giving a result of $21.21 \pm 0.0776 \mathrm{mgl}^{-1}$ of $\mathrm{Sn}$. The sample solutions were calculated from the calibration curve then subtracted from above value to give their true respective value. As expected the composite pot samples confirmed, the method for spiking sediment with TBT was successful and results showed no uptake of TBT (reported as total Sn) in samples 1-9. However samples 10, 11 and 12 reported a slight uptake of TBT, 1.22, 0.61 and $1.46 \mathrm{mg} / \mathrm{kg}$ of Sn respectively or possibly degrading products DBT and MBT. Interestingly samples 10, 11 and 12 represented pots spiked with $50 \mathrm{mg} / \mathrm{kg}$ of TBT a magnitude five times higher than any reported contaminated site.

\subsection{Sediment Analysis by GC-MS}

Under favourable conditions bacteria inoculum C7 (KX881905) and C22 (KX881904) can biologically degrade TBT sequentially into its less toxic specie dibutyltin (DBT) by the loss of an alkyl group. TBT $\left(\mathrm{C}_{12} \mathrm{H}_{27} \mathrm{Sn}^{+}\right)$ forms a $\beta$-hydroxybutyl-dibutyltin $\left(\mathrm{C}_{12} \mathrm{H}_{27} \mathrm{OSn}^{+}\right)$through dioxygenases i.e. incorporating an oxygen atom into the substrate through enzyme activity to form DBT $\left(\mathrm{C}_{8} \mathrm{H}_{18} \mathrm{Sn}^{2+}\right)$ and a methyl ethyl ketone. Followed by DBT dioxygenase of $\beta$-hydroxybutyl butyltin $\left(\mathrm{C}_{8} \mathrm{H}_{18} \mathrm{OSn}^{2+}\right)$ to monobutyltin (MBT) $\left(\mathrm{C}_{4} \mathrm{H}_{9} \mathrm{Sn}^{3+}\right)$ and a methyl ethyl ketone becoming increasingly less toxic in the process. In addition MBT may degrade finally into inorganic tin which is stable and of low toxicological risk to humans and other mammals (Figure 3) [1,2,17]. Nonetheless information on the mechanism of sequential dealkylation of TBT is still limited therefore, for this study gas chromatography (GC) was employed for the analysis of sediment on seedlings roots for the identification of TBT and degrading species to determine the mechanism of interest. Gas chromatography (GC) is the most universal instrument used for organotin analysis due to its high resolution, separation ability and sensitivity of detectors available $[7,10,12,13,14,15]$. The GC-MS was operated in full scan mode and selective ion monitoring mode (SIM) which allowed for detection of specific analysts and increased sensitivity relative to full scan mode. As such in
SIM mode the instrument is set to identify only masses of interest (TBT, DBT and MBT) instead of all masses of the sample. Typically two to four ions are monitored per compound and the ratios of those ions will be unique to the analyte of interest, Table 1.Thus sediment samples collected from roots of harvested seedlings Hordeum vulgare and sediment from control pots were analysed by GC-MS to determine TBT degradation rate. Also the degradation products dibutyltin (DBT) and monobutyltin (MBT). However, prior to analysing the sediment samples by GC-MS, optimum GC and detector conditions were established followed by accurate sample preparation including, derivatisation and liquid-liquid extraction to increase separation, identification and quantification. An analytical procedure for separation and identification of organotin compounds was optimised on standard samples (Figure 7) and then compared to sediment samples. The challenges posed and the main critical steps in organotin analysis was the extraction and derivatisation of MBT and DBT since low yields can occur at this stage, leading to an underestimation of their content in the samples due to their more ionic nature. Ethylation by sodium tetraethylborate (NaBEt4) was the preferred option for derivatisation in this study, by which the chlorine atoms attached to the butyltin compounds are removed by the reagent and replaced with ethyl groups to achieve more volatile ethyl-derivative compounds $[7,10,13]$. The method showed reasonable derivatisation effectiveness for organotin compounds in sediment samples and produced three distinct (ethyl derivative) peaks, of TBT, DBT and MBT (Figure 7).

Qualitative analysis was carried out comparing peak retention time (RT) of standard solutions against peak retention times of sediment samples (Table 1 ). All so a comparison was made of the ion trap mass spectra of the root/ sediment samples against the standard ion trap mass spectra, from the NIST reference Mass Spectrometry Library. Results show the characteristic ions for the three ethyl- derivatives and give a good to fair average match factor according to the NIST standard reference database (Table 1, Figure 8) [33].

Quantitative analysis was carried out on the (ethyl derivatives) of TBT, DBT and MBT in sediment samples removed from the roots of Hordeum vulgare seedlings with or without bacteria inoculum $(n=15)$, measuring peak area from the 3 distinctive peak in the chromatographs. Five point calibration curves were generated using triplicate injections of $1 \mu \mathrm{l}$ of TBT, DBT and MBT standards which had good linearity with $\mathrm{R}^{2}$ values of 0.999245 for MBT, 0.99919 for DBT and 0.991232 for TBT. Additionally the following limits of quantification (LOQ) were obtained $0.5,0.7$, and $0.8 \mathrm{mg} / \mathrm{kg}$ for TBT, DBT and MBT respectively. Sediment samples from the root of seedlings spiked with $50 \mathrm{mg} / \mathrm{kg}$ samples exhibited a breakdown of TBT after 30 days through sequential dealkylation. Results show sediment samples with bacteria inoculum C7/C22 decreased TBT by $82 \%$ and $80 \%$ respectively (Figure 9). In addition root sediment samples (10 mg/kg) containing Hordeum vulgare + C22/C7 inoculum showed approximately a $73.5 \%$ degradation of TBT with a 19\%, accumulation of DBT and 37\% accumulation of MBT (Figure 9). Sediment samples (1 mg/kg), GC-MS analysis only detected a trace amount of MBT below the LOQ. 


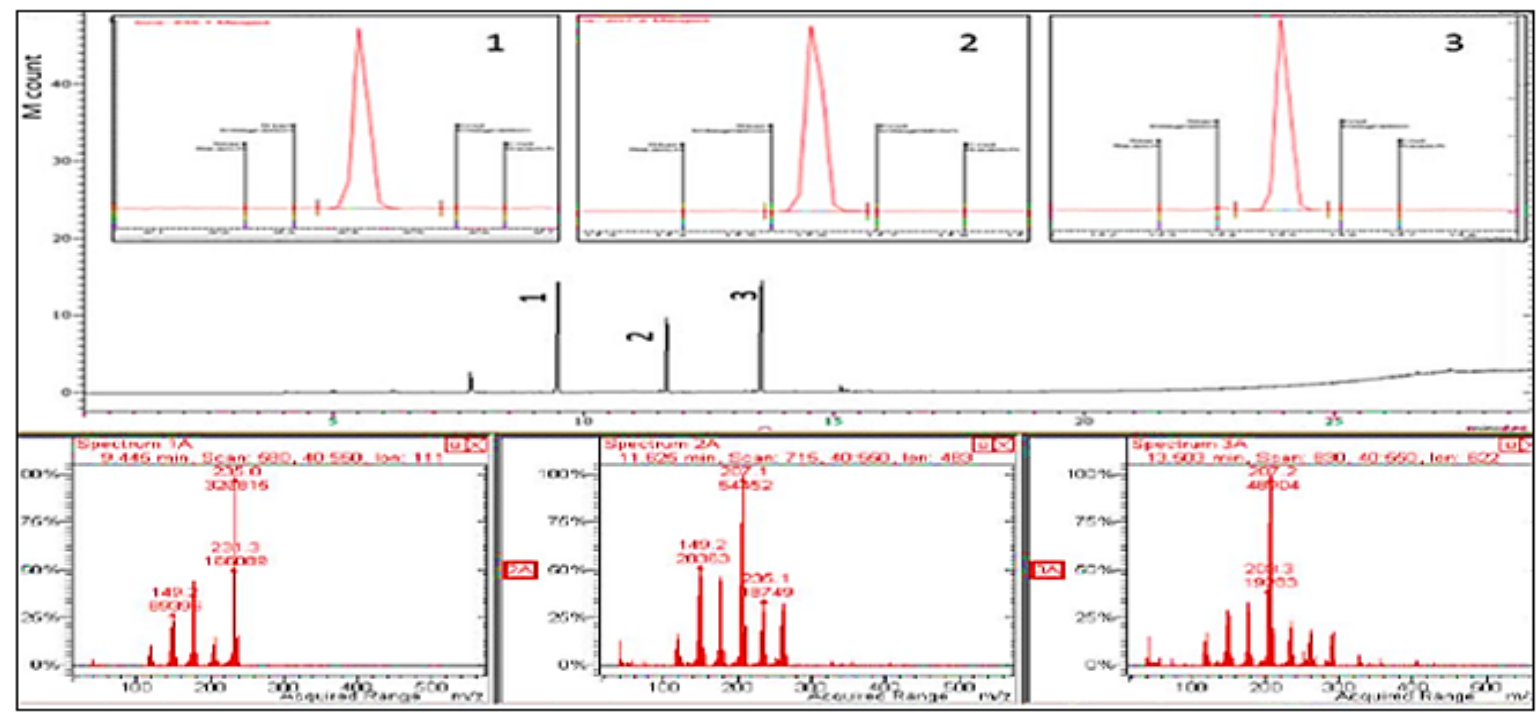

Figure 7. Identification of TBT (peak 3), DBT (peak 2) and MBT (peak 1) of known samples (Mass spectrum of each compound and chromatographic separation). Showing unique fragmentation pattern of eluted organotins in order to identify according to its mass to charge ratio $(\mathrm{m} / \mathrm{z})$ and determine retention times

Table 1. Organotin species characteristics and associated retention times mean \pm standard deviation $(\sigma) n=42$

\begin{tabular}{ccccccc}
\hline Peak & $\begin{array}{c}\text { Compound } \\
\text { Name }\end{array}$ & Abbreviation & $\begin{array}{c}\text { Average match } \\
\text { factor }\end{array}$ & $\begin{array}{c}\text { Characteristic Ions } \\
(\mathbf{m} / \mathbf{z})\end{array}$ & $\begin{array}{c}\text { Standards Retention } \\
\text { time (min) }\end{array}$ & $\begin{array}{c}\text { Samples Average } \\
\text { Retention time (min) }\end{array}$ \\
\hline 1 & Butyltriethyl- & MBT & 789 & $179,149,235$ & 9.434 & $9.422 \pm \sigma 0.00027$ \\
\hline 2 & Dibutyldiethyl- & DBT & 807 & $149,207,263$ & 11.614 & $11.60 \pm \sigma 0.00030$ \\
\hline 3 & Tributylethyl- & TBT & 789 & $177,207,235$ & 13.497 & $13.515 \pm \sigma 0.00024$ \\
\hline
\end{tabular}
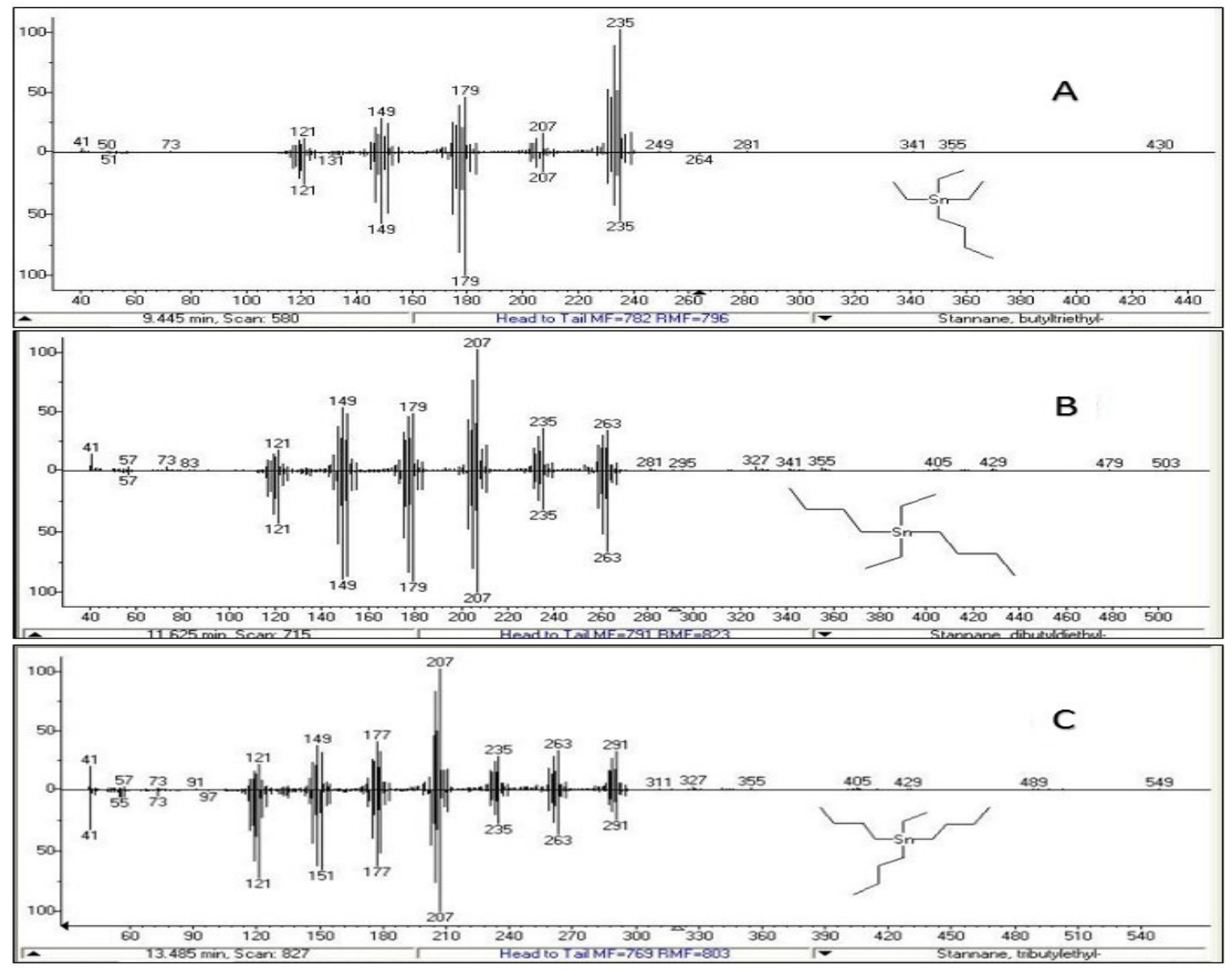

Figure 8. Typical mass spectrums (finger print) of ethyl-derivatives (A) MBT, (B) DBT and (C) TBT respectively showing a mirror image comparison of the characteristic ions found on Hordeum vulgare root sediment sample inoculated with bacteria inoculum C22 (Top spectrums) against the NIST library (underlying spectrums), (y-axis, relative abundance, $x$-axis, $m / z$ ) 


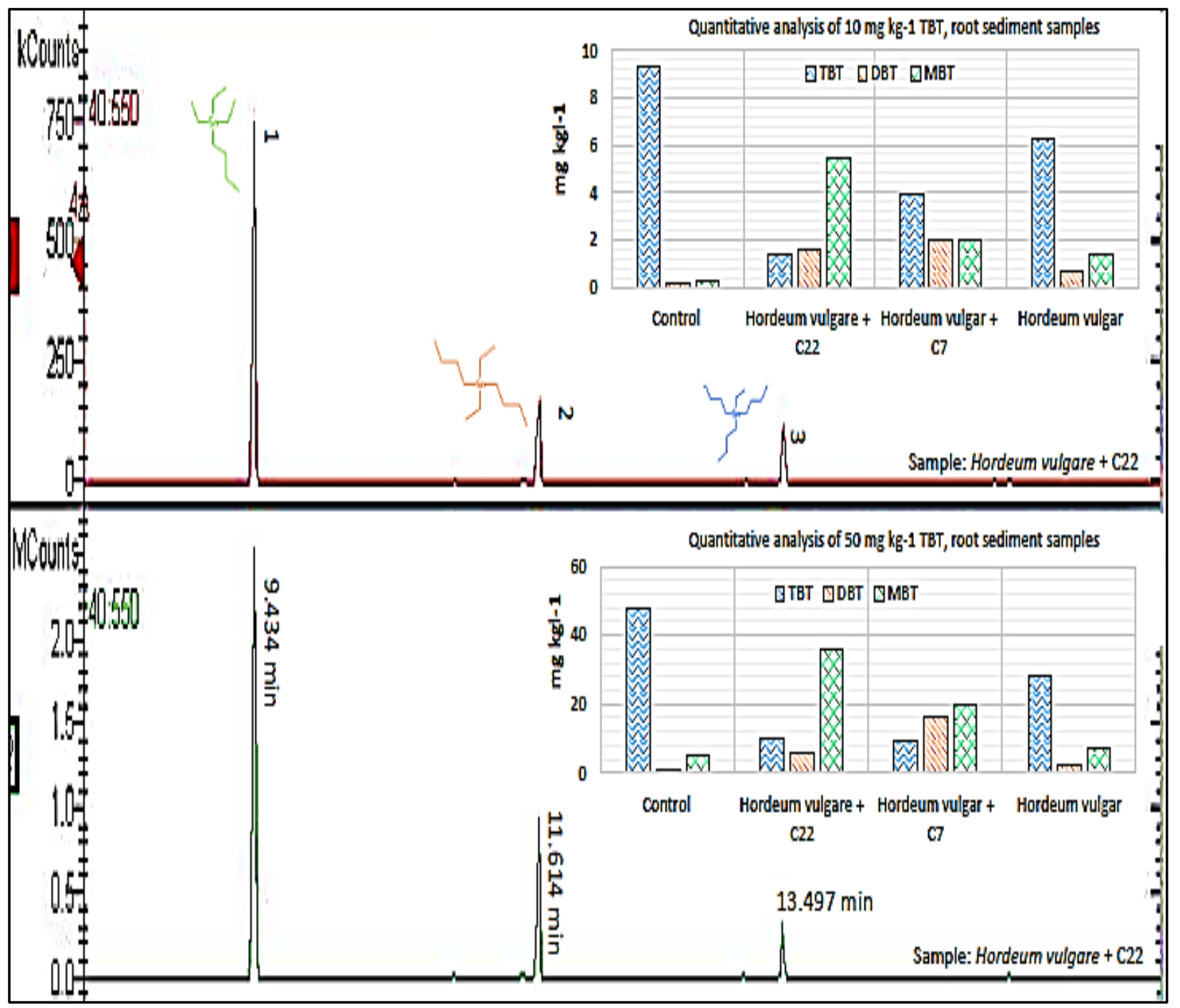

Figure 9. Quantitative analysis of sediment samples isolated from the roots of Hordeum Vulgare seedlings with/without bacteria inoculum C7 (KX881905), C22 (KX881904) and control samples. Bar graph inserts (Top $10 \mathrm{mg} \mathrm{Kg}^{-1}$ and Bottom $50 \mathrm{mg} \mathrm{Kg}^{-1}$ of TBT). Chromatographic separation (SIM mode) from sediment isolated from the roots of Hordeum Vulgare seedlings combined with bacteria inoculum C22 demonstrating TBT (peak 3) degradation to DBT (peak 2) and MBT (peak 1) detector response (y-axis) against retention time (x-axis)

\section{Conclusion}

To conclude the seedlings of Brassica napus showed very poor growth during the 30 day pot trial in the sediment thus no analytical analysis was carried out. Therefore Hordeum vulgare seedlings were the ideal candidate plant species, statically and after analytical analysis was carried out on the seedlings $(\mathrm{n}=45)$ after the 30 day pot trial in contaminated sediment and noncontaminated soil. In brief results from the statistical analysis (ANOVA, Two-Factor with Replication) on biomass indicates Hordeum vulgare seedlings can cultivate in TBT polluted sediments/controls and have a significant production of biomass compared to control samples in soil. Total Sn analysis showed there was little to no uptake of TBT into the seedlings. Also by combining Hordeum vulgare seedlings with bacteria inoculant C22 (KX881904) TBT degradation was in enhanced by $80 \%$. Further GC-MS analysis showed the breakdown of TBT to its less toxic compounds DBT and MBT thus remediating the polluted sediment. Nature-based solutions have the potential to remediated polluted sites and can have economic benefits from the by-product such as biofuels and biomaterials. However more pilot-scale and field scale studies are necessary.

\section{Conflict of Interests}

The authors declare they have no conflict of interests.

\section{Acknowledgements}

The work described in this paper was fully funded by ITC Presidents Research Fellowship Programme.

\section{References}

[1] Antizar-Ladislao, B. (2008). Environmental levels, toxicity and human exposure to tributyltin (TBT)-contaminated marine environment. A review. Environment International, 34(2), pp. 292-308.

[2] Kotrikla, A. (2009). Environmental management aspects for TBT antifouling wastes from the shipyards. Journal of Environmental Management, 90, pp. S77-S85. 
[3] Du, J., Chadalavada, S., Chen, Z. and Naidu, R. (2014). Environmental remediation techniques of tributyltin contamination in soil and water: A review. Chemical Engineering Journal, 235, pp. 141-150.

[4] Gadd, G. (2000). Microbial interactions with tributyltin compounds: detoxification, accumulation, and environmental fate. Science of The Total Environment, 258(1-2), pp. 119-127.

[5] Khanolkar, D., Dubey, S. and Naik, M. (2015). Biotransformation of tributyltin chloride to less toxic dibutyltin dichloride and monobutyltin trichloride by Klebsiella pneumoniae strain SD9. International Biodeterioration \& Biodegradation, 104, pp. 212-218.

[6] Silva, P., Silva, A., Mendo, S. and Loureiro, S. (2014). Toxicity of tributyltin (TBT) to terrestrial organisms and its species sensitivity distribution. Science of The Total Environment, 466-467, pp. 1037-1046.

[7] Morabito, R. (2000). Derivatization methods for the determination of organotin compounds in environmental samples. TrAC Trends in Analytical Chemistry, 19(2-3), pp. 113-119.

[8] Cruz, A., Henriques, I., Sousa, A., Baptista, I., Almeida, A., Takahashi, S., Tanabe, S., Correia, A., Suzuki, S., Anselmo, A. and Mendo, S. (2014). A microcosm approach to evaluate the degradation of tributyltin (TBT) by Aeromonas molluscorum Av27 in estuarine sediments. Environmental Research, 132, pp. 430-437.

[9] Zhou, Q., Jiang, G. and Liu, J. (2002). Organotin Pollution in China. The Scientific World JOURNAL, 2, pp. 655-659.

[10] TAKEUCHI, M., MIZUISHI, K. and HOBO, T. (2000) Determination of Organotin Compounds in Environmental Samples. Analytical Sciences, 16(4), pp. 349-359.

[11] Moscoso-Pérez, C., Fernández-González, V., Moreda-Piñeiro, J., López-Mahía, P., Muniategui-Lorenzo, S. and Prada-Rodríguez, D. (2015). Determination of organotin compounds in waters by headspace solid phase microextraction gas chromatography triple quadrupole tandem mass spectrometry under the European Water Framework Directive. Journal of Chromatography A, 1385 pp. 85-93.

[12] Jones, M.A., Stauber, J., Apte, S., Simpson, S., Vicente-Beckett, V., Johnson, R., and Duivenvoorden, L. (2005) A risk assessment approach to contaminants in Port Curtis, Queensland, Australia. Marine Pollution Bulletin. 51(1-4), pp. 448-458.

[13] Negri, A.P., Smith, L.D. Webster, N.S. and Heyward, A.J. (2002) Understanding ship-grounding impacts on a coral reef: potential effects of anti-foulant paint contamination on coral recruitment. Marine Pollution Bulletin. 44(2), pp. 111-117.

[14] Negri, A.P., Hales, L.T., Battershill, C., Wolff, C. and Webster, N.S. (2004) TBT contamination identified in Antarctic marine sediments. Marine Pollution Bulletin. 48, pp. 1142-1144.

[15] Ofoegbu, P., Simão, F., Cruz, A., Mendo, S., Soares, A. and Pestana, J. (2016). Toxicity of tributyltin (TBT) to the freshwater planarian Schmidtea mediterranea. Chemosphere, 148, pp. 61-67.

[16] Bramhachar, P., Kumar, B., Deepika, K. and Gnanender, S. (2014). Alcaligenes sp. Strain VBAK101: A Potent Tributyltin Chloride (TBTCL) Resistant Bacteria Isolated from Vishakaptanam Shipping Harbour Sediments. Research Journal of Microbiology, 9(2), pp. 82-94.

[17] Dubey, S. and Roy, U. (2003). Review: Biodegradation of tributyltins (organotins) by marine bacteria. Applied Organometallic Chemistry, 17(1), pp. 3-8.
[18] Cruz, A., Anselmo, A., Suzuki, S. and Mendo, S. (2015) Tributyltin (TBT): A Review on Microbial Resistance and Degradation. Critical Reviews in Environmental Science and Technology, 45(9), pp. 970-1006.

[19] Cruz, A., Caetano, T., Suzuki, S. and Mendo, S. (2007) Aeromonas veronii, a tributyltin (TBT)-degrading bacterium isolated from an estuarine environment, Ria de Aveiro in Portugal. Marine Environmental Research, 64(5), pp. 639-650.

[20] Jeong, B., Hong, S., Choi, Y., Kumaran, R., Kim, M., Kim, S. and Kim, H. (2011). Isolation of Tributyltin Chloride Resistance Bacteria and Rapid Electrochemical Determination of Bacterial Organotin Degradation Activity. Bulletin of the Korean Chemical Society, 32(1), pp. 356-358.

[21] Sakultantimetha, A., Keenan, H., Dyer, M., Beattie, T. Bangkedphol, S., Songsasen, A., Galvez, R., Dyer, M. and Dean, S. (2009). Isolation of Tributyltin-Degrading Bacteria Citrobacter braakii and Enterobacter cloacae from Butyltin-Polluted Sediment. Journal of ASTM International, 6(6), p.102120.

[22] Germaine, K., Byrne, J., Liu, X., Keohane, J., Culhane, J., Lally, R., Kiwanuka, S., Ryan, D. and Dowling, D. (2015). Ecopiling: a combined phytoremediation and passive biopiling system for remediating hydrocarbon impacted soils at field scale. Frontiers in Plant Science, 5.

[23] Jin, J., Yang, L., Chan, S., Luan, T., Li, Y. and Tam, N. (2011) Effect of nutrients on the biodegradation of tributyltin (TBT) by alginate immobilized microalga, Chlorella vulgaris, in natural river water. Journal of Hazardous Materials, 185(2-3), pp. 1582-1586.

[24] E. (2008). Genomics of cellulosic biofuels. Nature, 454(7206), pp 841-845.

[25] Regalbuto, J. (2009). Cellulosic Biofuels--Got Gasoline? Science, 325(5942), pp. 822-824.

[26] Huber, G., Iborra, S. and Corma, A. (2006). Synthesis of Transportation Fuels from Biomass: Chemistry, Catalysts, and Engineering. ChemInform, 37(52).

[27] Huber, G. and Corma, A. (2007). Synergies Between Bio- and Oil Refineries for the Production of Fuels from Biomass. ChemInform, 38(50).

[28] Nigam, P. and Singh, A. (2011). Production of liquid biofuels from renewable resources. Progress in Energy and Combustion Science, 37(1), pp. 52-68.

[29] Finnegan, C., Ryan, D., Enright, A-M. and Garcia-Cabellos, G. (2017). Gas Chromatographic Approach to Evaluate the Efficacy of Organotin Degrading Microbes. International Journal of Environmental Bioremediation \& Biodegradation. 5(1), pp. 18-26.

[30] Zou, X., Zeng, L., Guang-yuan, L., Cheng, Y., Xu, J., Zhang, X. (2015). Comparison of transcriptomes undergoing waterlogging at the seedling stage between tolerant and sensitive varieties of Brassica napus L: Journal of Integrative Agriculture, vol. 14, pp. 17-23.

[31] Çavuşoğlu, K. and Kabar, K. (2010). Effects of hydrogen peroxide on the germination and early seedling growth of barley under $\mathrm{NaCl}$ and high temperature stresses. EurAsian Journal of Biosciences, pp. 70-79.

[32] Horvai, G. (2014). Gary D. Christian, Purnendu (Sandy) Dasgupta and Kevin Schug: Analytical chemistry, 7th ed. Analytical and Bioanalytical Chemistry, 406(22), pp. 5255-5256.

[33] Scott, D. (1990). The NIST/EPA/MSDC mass spectral database, personal computer versions 1.0 and 2.0. Chemometrics and Intelligent Laboratory Systems, 8(1), pp. 3-5. 